\title{
INTERAÇÃO UNIVERSIDADE E COMUNIDADE: POSSIBILIDADES DO TRABALHO COM DIREITOS HUMANOS
}

\author{
J. V. de Mendonça ${ }^{1}$; A. E. O. de Lima ${ }^{2}$ \\ ${ }^{1}$ Aluna do curso de Gestão de Políticas Públicas pela Universidade Federal do Ceará (UFC), bolsista do trabalho de extensão sob \\ o código(CP.2017.PJ.059); E-mail: jessica.venancio.m@ hotmail.com; ${ }^{2}$ Professora Dra. do Departamento de Economia Doméstica, do \\ curso de Gestão de Políticas Públicas da UFC, coordenadora dos trabalhos de extensão sob os códigos: (CP.2017.PJ.059); \\ (CCAO.2015.PJ.0280; ( CP.20017.PJ.061).E-mail: manuufc@hotmail.com
}

Artigo submetido em Julho/2016 e aceito em Novembro/2017

\section{RESUMO}

Este artigo é fruto de uma reflexão e estudo após um trabalho realizado na disciplina Estado e Direitos Humanos no Brasil do curso de Gestão de Políticas Públicas da Universidade Federal do Ceará (UFC). A atividade foi sugerida a partir do projeto de extensão em andamento, intitulado: Mapeamento de Instituições da Comunidade do Pici para uma proposta de Educação em Direitos Humanos, coordenada pela docente da disciplina. O projeto consistia na visita a instituições na comunidade do Pici, localizada na circunvizinhança desta Universidade. Nesse contexto, esse trabalho apresenta como objetivo geral verificar a participação dos alunos nessa atividade de pesquisa e extensão. Especificamente, verificar as percepções dos alunos em relação a essa experiência e descrever suas impressões. Partindo de uma pesquisa do tipo qualitativa, a metodologia consistiu em aplicação de um questionário semi-estruturado e análise dos dados coletados. A partir dos relatos foi possível perceber quão importante são essas atividades de pesquisa e extensão para a formação profissional, pois são nelas que os alunos se deparam com a prática da teoria estudada em sala. Esse trabalho chamou atenção, por ser realizado em uma área física tão próxima da Universidade e ao mesmo tempo tão distante, que carece de um debate maior sobre os Direitos Humanos, pois estão inseridas em uma realidade social desigual, cuja maior parte dos moradores e jovens não se sente pertencentes a esse espaço e desconhece seus direitos, fato que demonstra a falta de conhecimentos para cobrar uma efetivação de seus direitos fundamentais.

PALAVRAS-CHAVE: Integração; Pesquisa. Extensão; Oportunidades; Direitos Humanos.

\section{INTERACTION UNIVERSITY AND COMMUNITY: POSSIBILITIES OF WORD WITH HUMAN RIGHTS}

\begin{abstract}
This article is the result of a reflection and study after a work carried out in the State and Human Rights in Brazil course of the Public Policy Management course of the Federal University of Ceará (UFC). The activity was suggested from the ongoing extension project, entitled: Mapping Institutions of the Pici Community for a Human
\end{abstract}

Rights Education proposal, coordinated by the teacher of the discipline. The project consisted of visiting institutions in the community of Pici, located in the vicinity of this University. In this context, this work presents a general objective to verify the participation of students in this research and extension activity. Specifically, check students' 
perceptions of this experience and describe their impressions. Starting from a qualitative research, the methodology consisted in the application of a semi-structured questionnaire and analysis of the data collected. From the reports it was possible to perceive how important these activities of research and extension for the professional formation are, because they are in them that the students are faced with the practice of the theory studied in room. This work attracted attention, because it was carried out in a physical area so close to the University and at the same time so distant, that it needs a greater debate on Human Rights, since they are inserted in an unequal social reality, whose majority of the inhabitants and young people does not feel belonging to this space and is unaware of their rights, a fact that demonstrates the lack of knowledge to collect an effectiveness of their fundamental rights.

KEYWORDS: Design. Crafts. Clothing

\section{INTRODUÇÃO}

A Universidade Federal do Ceará (UFC) é uma das faculdades de maior renome do Brasil, devido a sua qualidade e excelência. Segundo uma reportagem recente na página da UFC, esta tem avançado no Exame Nacional de Desempenho de Estudantes (Enade), em que dos 11(onze) cursos avaliados, 6 (seis) alcançaram o conceito máximo (nota 5). Vale ressaltar que apenas 6\% dos cursos avaliados pelo Enade no Brasil, obtiveram essa nota. Esse reconhecimento também se estende a nível internacional: em maio de 2013 o G1-CE publicou que a UFC ficou em posições consideráveis entre as melhores universidades em 2013, no ranking Scimago de Instituições Ibero-Americanas (Ibero-Americano Scimago Institutions Ranking - SIR) que faz a análise da produção científica de quase 3.300 instituições de pesquisa em 106 países e no Ranking Mundial de Universidades Quacquarelli Symonds (Quacquarelli Symonds World University Rankings - QS-WUR). A UCF ficou na $48^{\circ}$ posição entre os países ibero-americanos, no $23^{\circ}$ lugar entre os países da América Latina e $15^{\circ}$ lugar entre as instituições brasileiras.

A Universidade é um espaço de aprendizagem contínua e processual, nesse espaço, experiências práticas tornam esse processo mais rico, formando com qualidade o universitário para a vida acadêmica e profissional. Não é de se admirar que a UFC invista em tantos projetos e programas de pesquisa e extensão, segundo dados da Análise da Série Histórica de Dados Básicos da UFC no Portal da UFC, (corresponde a um período de dez anos, de 2003 à 2013): Houve crescimento de 36,6\% nas bolsas monitoria de graduação e de $19 \%$ nas de iniciação acadêmica; as ações de extensão aumentaram 25,11\% em relação ao ano de 2012, o que significou mais de 900.000 beneficiados. Desta forma os contratos e convênios de 
extensão tiveram um acréscimo de 48,7\% em relação a 2012; aumentou também, os estágios de universitários nas empresas, com um crescimento de 14,5\% de 2012 a 2013.

Nesse contexto é de vital importância reconhecer o quão valorativo para a formação profissional são as experiências de pesquisa e extensão do qual os alunos da UFC são normalmente submetidos e cobrados cotidianamente pelos docentes. Característica aparentemente mais valorizada em universidades públicas, na qual o aluno é incentivado e em alguns casos sujeito (para realização de trabalhos e obtenção de notas) a realizar essas atividades. Este trabalho é fruto dessas experiências de campo e visa apresentar as percepções e concepções desta experiência por todos os alunos envolvidos. Para atingir tal objetivo foi necessário realizar entrevistas, acerca do trabalho desenvolvido.

Quanto às discussões relativas aos Direitos Humanos, ressalta-se que o plano nacional de Educação dessa temática informa que a concepção de Direitos incorpora a compreensão de cidadania democrática, ativa e planetária, embasadas nos princípios de liberdade, da igualdade, da diversidade, da universalidade, indivisibilidade e interdependência dos direitos. Informa ainda que o contexto nacional, historicamente tem se caracterizado por desigualdades e pela exclusão econômica, social, racial e cultural o que dificulta avanços na área de Direitos Humanos.

\section{DIREITOS HUMANOS DESAFIOS E POSSIBILIDADES}

Uma educação voltada para os Direitos Humanos no nosso país se revela timidamente, e essa educação vem tomando corpo graças à mobilização dos movimentos sociais. Como resultados, hoje existem programas nacionais, estaduais e municipais de Direitos Humanos, o Estatuto da Criança e do Adolescente-ECA, as legislações de combate à discriminação racial e à tortura, bem como as recomendações das Conferências Nacionais de Direitos Humanos, porém ainda não é suficiente para inibir tais violações.

Oficialmente a educação voltada aos Direitos Humanos já é uma realidade. A resolução $\mathrm{n}^{\circ} 01$ de 30 de maio de 2012, estabelece Diretrizes Nacionais para Educação em Direitos Humanos, levando em consideração o que dispõe a Declaração Universal dos Direitos Humanos de 1948; a Declaração das Nações Unidas sobre a Educação e Formação 
em Direitos Humanos (Resolução A/66/137/2011); a Constituição Federal de 1988; a Lei de Diretrizes e Bases da Educação Nacional (Lei no 9.394/1996); o Programa Mundial de Educação em Direitos Humanos (PMEDH 2005/2014), o Programa Nacional de Direitos Humanos (PNDH-3/Decreto $n^{\circ}$ 7.037/2009); o Plano Nacional de Educação em Direitos Humanos (PNEDH/2006); e as Diretrizes Nacionais emanadas pelo Conselho Nacional de Educação, bem como outros documentos nacionais e internacionais que visem assegurar o direito à educação a todos (as).

A obrigatoriedade da Educação em Direitos Humanos está expressa no Artigo 2 parágrafo $2^{\circ}$ desta resolução: "aos sistemas de ensino e suas instituições cabe a efetivação da Educação em Direitos Humanos, implicando a adoção sistemática dessas diretrizes por todos (as) os envolvidos(as) nos processos educacionais". (BRASIL, 2012).

Embora tenhamos respaldo jurídico nessa lei, a Educação em Direitos Humanos ainda não faz parte da prática nem dos currículos da maioria das nossas escolas, assim como outros direitos que estão inscritos oficialmente em textos legais e por isso torna-se cada vez mais obscuro a internalização por todos da necessidade de igualdade e de defesa da dignidade humana.

Atualmente nos meios de comunicação de massa, é comum escutarmos algo sobre Direitos Humanos, e se torna mais corriqueiro ainda escutar nos programas policiais. Mas pouca gente entende o que de fato os Direitos Humanos defendem. Na concepção de muitos, os Direitos Humanos foi criado para defender bandido. Compreendemos que essa discussão só ocorre porque as pessoas não tiveram oportunidade de observar ou estudar minuciosamente a questão dos Direitos Humanos.

Direitos Humanos podem ser conceituados como aquele direito que pertence ao próprio ser humano, mas pode ser também discutido sobre o prisma de críticos que corrobora para uma reflexão mais aprofundada. Bobbio, (1992), por exemplo, considera que direitos do homem é uma expressão muito vaga, pois a considera mal definível, variável, heterogênea e antinômica. Essa discussão leva a uma questão maior, a saber: a proteção dos Direitos Humanos.

\section{MATERIAIS E MÉTODOS}


A atividade que iniciou a reflexão para essa explanação fazia parte de um trabalho correspondente a uma das notas da disciplina de Estado e Direitos Humanos no Brasil. Este trabalho era limitado ao bairro do Pici, por ser uma comunidade localizada nas imediações da Universidade, levando-se em consideração a proximidade e a necessidade de formação em Direitos Humanos em uma comunidade da periferia, portanto, tida como carente e com poucos recursos e instruções de seus direitos.

Além do fato dessa atividade integrar parte das ações do projeto de extensão intitulado: Mapeamento de Instituições da Comunidade do Pici para uma proposta de Educação em Direitos Humanos, na qual as instituições escolhidas pelos alunos seriam as primeiras a serem mapeadas e dentre elas, uma seria escolhida, após alguns critérios a serem observados, critérios estes, já apresentados no referido projeto, para a consolidação da primeira formação em Direitos Humanos.

Para a realização dessa tarefa dividiu-se a turma composta de doze alunos em cinco equipes de duplas ou trios, cada equipe ficaria responsável por uma instituição de seu interesse. $\mathrm{O}$ objetivo desde trabalho disciplinar era pesquisar e escolher uma das organizações que trabalhasse de alguma forma com Direitos Humanos. A proposta era visitar, realizar entrevistas e socializar com toda a turma levando em conta os seguintes pontos: 1 . Nome da Instituição, 2. Histórico e objetivos, 3. Estrutura e organização, 4. Público alvo e campo de atuação e 5. Dificuldades e desafios (da instituição e do trabalho).

Pormenorizando este último ponto, a partir dessa experiência de extensão relatada pelos alunos, pôde-se perceber o quão difícil e desafiante foi o processo de constituição desse trabalho. O primeiro empecilho relatado foi o de entrar em contato com as instituições, que não tinham sites e quando possuíam seus contados estavam indisponíveis ou desatualizados. O segundo, quando possuíam sites, apresentavam uma composição de ações muito amplas, não deixando claro sua atuação e projetos junto à comunidade.

É importante ressaltar que foi observado na pesquisa e descrito pelas pessoas que compõe o quadro de funcionário das instituições visitadas, que muitas entidades não existem, são "fantasmas", funcionando apenas em período eleitoral para angariação de votos, a partir desse fato, é necessário um mapeamento e verificação minuciosa dessas instituições, para somente posterior parceria. Por último, a dificuldade na localização das instituições, apesar de 
serem próximas a UFC as mesmas estão localizadas em uma comunidade que se apropriou ou ocupou as terras, sem o prévio planejamento urbano, pois o bairro é disposto em ruas irregulares e tortuosas, com travessas sem saída ou sem acesso a carro devido o estreito diâmetro, ademais da restrita disponibilidade de transporte público que dê acesso as ruas mais internas do bairro.

Por meio da percepção da relevância e das possibilidades que esse trabalho de campo realizado na disciplina pôde proporcionar, independente das dificuldades citadas, realizou-se este trabalho. Visto que segundo Minayo (2009) a pesquisa qualitativa aborda questões mais particulares, "ela trabalha com o universo dos significados, dos motivos, das aspirações, das crenças, dos valores e das atitudes" (MINAYO, 2009, p. 21), é sobre esse conjunto de características humanas que trabalhamos, tentando extrair a essência do conhecimento advindo da realidade social, tanto questionada na academia.

Ainda nessa perspectiva, Minayo (2009) diz que "esse conjunto de fenômenos humanos é entendido aqui como parte da realidade social, pois o ser humano se distingue não só por agir, mas por pensar sobre o que faz e por interpretar suas ações dentro e a partir da realidade vivida e partilhada com seus semelhantes." (MINAYO, 2009, p. 21). Com base nisto, foi levantado na entrevista questões para que os entrevistados pensassem a respeito de suas opiniões pré e pós experiências de trabalho.

Utilizou-se um roteiro semi-estruturado, composto de seis perguntas relacionadas ao processo de realização do trabalho da disciplina Estado e Direitos Humanos no Brasil: 1. O que você pensou preliminarmente da proposta da professora de ir a campo e visitar uma instituição da comunidade? 2. Qual foi a instituição visitada e por qual motivo a escolheu? 3. O que achou dessa experiência, ela lhe enriqueceu de alguma maneira? 4. Sua opinião inicial sobre esse trabalho de campo permaneceu a mesma após a visita? 5. Como você acha que a Universidade, os universitários e professores podem contribuir com as demandas da instituição que você visitou? 6. Qual a importância que você daria para o trabalho de extensão da universidade para a comunidade?

Este roteiro foi aplicado por meio de entrevista, que segundo Cruz Neto (2002): não significa uma conversa despretensiosa e neutra, uma vez que se insere como meio de coleta dos fatos relatados pelos atores, enquanto sujeitos-objetos da pesquisa que vivenciam uma determinada realidade que está sendo focalizada. [...] Nesse sentido, a entrevista, um termo bastante genérico, está sendo por nós entendida como uma conversa a dois com propósitos bem definidos. (CRUZ NETO, 
Dessa forma a entrevista foi realizada com cinco alunos, escolhidos aleatoriamente e que participaram da disciplina, para adquirir dados primários e subjetivos, que "se relaciona aos valores, às atitudes e às opiniões dos sujeitos entrevistados” (CRUZ NETO, 2002, p. 58), sobre a avaliação acerca desse trabalho e da própria experiência de trabalho de campo, assim como, das suas perspectivas e possibilidades.

\footnotetext{
De acordo com Fonseca (2002), a pesquisa possibilita uma aproximação e um entendimento da realidade a investigar, como um processo permanentemente inacabado. Ela se processa através de aproximações sucessivas da realidade, fornecendo subsídios para uma intervenção no real. (GERHARDT \& SILVEIRA, 2009, p. 36)
}

Com isso, o roteiro de entrevista visava extrair as percepções do processo de pesquisa e avaliação do trabalho sugerido pela disciplina, com o objetivo de verificar as suas percepções sobre a experiência de extensão vivida, assim como, averiguar a importância que os estudantes atribuíram às atividades de extensão e pesquisa da universidade.

\section{RESULTADOS E DISCUSSÕES}

Em geral a proposta foi considerada positiva, por possibilitar novas oportunidades de conhecimento e prática, isso é visível na fala dos alunos, "achei desafiador, pois uma coisa é vermos a teoria e outra é conhecer realmente como funciona, onde fica, sentir a instituição e sua política". (ENTREVISTADO/A 4, 2017) "Achei a ideia muito interessante, principalmente por ser uma "quebra" no cotidiano das aulas, como também a possibilidade de conhecer e compartilhar a experiência de visita a uma instituição voltada aos Direitos Humanos.” (ENTREVISTADO/A 5, 2017).

A partir do relato dos alunos foi observado que a maior crítica era o espaço de pesquisa limitado, pois se restringiu as opções de instituições no bairro do Pici. Ademais, por este ser uma comunidade da periferia, que constantemente é cenário de delitos e crimes, o bairro sugerido se configurava como perigoso o que deixou os alunos receosos em realizar as visitas. Além disso, houve a problemática do acesso a essas instituições, uma vez que não havia o conhecimento de uma linha de ônibus da cidade que realizasse o translado para chegar às instituições, sendo assim a única opção era todas as equipes ir de carro particular ou fretado, tanto por questões de acesso como de segurança. 
Outra problemática, ainda relacionada ao trabalho, foi o entendimento da maioria de que o local por está atrelado ao projeto de extensão, não poderia mudar, fato que expôs os alunos a esses problemas. Apesar do fato não ter agradado a todos os alunos, que entenderam estar fazendo parte do trabalho do projeto, o que não lhes era de função, nenhum deles desistiu ou externou para a professora suas angústias. Vale destacar que a proposta de atividade foi colocada como sugestão para todos nos primeiros dias de aula e nenhum discente se absteve, concordando em desenvolver as ações explicitadas.

As instituições em sua maioria foram escolhidas por questões de fácil acesso e contato, além da identificação com o tema trabalhado. Quando perguntados sobre a experiência, todos consideraram ter sido enriquecedora, pois contribui para sua formação profissional e pessoal, visto que acharam interessante conhecer e ver de perto o funcionamento da instituição e política, de forma também a dar visibilidade a essas organizações. Além de ter esse contato com a realidade e com a prática do que se estuda em sala, como relata a seguir um dos entrevistados.

Foi gratificante a experiência de ir a campo e conhecer uma instituição, em especial
por ouvir o relato de pessoas que vivenciam a rotina da instituição, que estão
envolvidos diretamente com todas as atividades e serviços prestados. Houve um
enriquecimento não só profissional como pessoal, visto que tivemos contato com um
projeto social que já beneficiou dezenas de pessoas, como também já trouxe
inúmeras melhorias para a comunidade. (ENTREVISTADO/A 5, 2017)

É interessante a visão diferenciada de uma das entrevistadas sobre o trabalho de sua organização visitada, que coincidentemente foi à mesma escolhida para ser a primeira a receber a formação do projeto. Isto se refere à instituição de mulheres Brilho da Lua, que é uma organização de caráter feminista com o trabalho de economia solidaria como forma de empoderamento dessas mulheres. Na visão da universitária o grupo vai além de sua proposta quando proporciona também o conforto e lazer nos seus encontros:

Achei incrível! Achei belíssimo o trabalho desenvolvido com as mulheres, abrir um espaço para que elas possam conversar entre si, sentirem-se úteis com o trabalho desenvolvido lá, o ambiente mesmo simples e mantido com dificuldade, mas acolhedor fiquei realmente tocada com tudo. É imprescindível em minha opinião ter esse contato real. (ENTREVISTADO/A 4, 2017)

A maior parte das opiniões iniciais sobre o trabalho não mudou após a visita, considerando tanto os aspectos positivos quanto negativos, com exceção de um(a) entrevistado(a) que considerou o bairro menos perigoso do que se esperava. Sobre a contribuição do meio acadêmico para com a comunidade foi geral as propostas de parcerias, 
projetos, capacitação, consultorias, oficinas, palestras, rodas de conversa e grupos de estudo, que foquem nos assuntos relevantes para a comunidade em geral e para o que cada instituição trabalha especificamente. Outra sugestão foi à própria divulgação dessas instituições e de seus trabalhos no meio acadêmico "até mesmo caso alguém queira se voluntariar para ficar participando, isso pode contribuir tanto para os alunos, quanto para a instituição que irão recebê-los.” (ENTREVISTADO/A 3, 2017)

Por fim, sobre a relevância do trabalho de extensão da Universidade para a comunidade, foi claro que todos concordaram que são atividades de grande importância e que os benefícios creditados pelos entrevistados, levaram em conta a necessidade da comunidade de sempre receber essa assistência e os benefícios mútuos que tal parceria traria:

É de extrema relevância, você poder ter a oportunidade de repassar conhecimento, ampliar e clarear horizontes e oportunidades para as pessoas da sociedade, pois ao meu ver, todo o conhecimento que obtemos não deve ter como finalidade nossa vida individual, mas sim poder modificar a realidade. (ENTREVISTADO/A 4, 2017)

Outro ponto significante é a intenção e a consciência dos universitários de oferecer, por meio dessa prática, o retorno de seus conhecimentos para a sociedade, isto é visível na fala dos entrevistados a seguir: "querendo ou não, a comunidade dá o recurso financeiro para a Universidade, e quando a gente é bolsista a gente está recebendo esse recurso, e o que a Universidade pode fazer é dar esse retorno em conhecimento de volta para as comunidades" (ENTREVISTADO/A 1, 2017).

A troca de conhecimentos e experiências. Quando estamos dentro da universidade, estamos nos capacitando para posteriormente servir a sociedade (comunidade). Quando temos a possibilidade de visitar um local, podemos vivenciar na prática os conhecimentos adquiridos, mas também adquirir novos no contato com profissionais, pessoas que já estão trabalhando. (ENTREVISTADO/A 5, 2017)

A partir disso, se percebe o entendimento da ação de extensão, de conhecer o real, de ter a prática, de aprender com o campo e também de poder ensinar e dar um retorno visível para a sociedade.

\section{CONCLUSÃO}

Apesar das dificuldades enfrentadas quanto a restrição do local, cuja localidade trouxe problemas iniciais, mas que foram superados no decorrer do trabalho, os alunos reconheceram as necessidades dessa comunidade tão próxima do Pici e verificaram que é imprescindível a 
ação da academia junto desta.

Da mesma forma, a partir dos próprios depoimentos, percebeu-se que os universitários reconheceram ser essencial essa prática do trabalho de campo para a sua construção pessoal e profissional. Considerando ainda que a integração e parceria da Universidade com a comunidade, por meio dessas organizações, é algo necessário e beneficente.

Percebeu-se também que as instituições aspiram maior integração e colaboração com o meio universitários, almejando que esta e seus componentes possam atuar junto delas, contribuindo com seus conhecimentos acadêmicos e técnicos, visando à melhora das condições de vida e bem-estar da comunidade.

Essa mesma perspectiva foi compartilhada por todos os alunos. Visto que, como graduandos em Gestão de Política Pública, perceberam a necessidade que a comunidade tem em ter acesso às diversas políticas públicas. Os entrevistados sugeriram que a integração da Universidade com a comunidade seja por meio de projetos, neste caso, são necessários projetos de extensão, cuja Universidade daria esse retorno direto de conhecimento e técnica para a comunidade.

Ademais, é necessário também pensar junto a essas instituições, que representam e auxiliam a comunidade, na atuação de outros acadêmicos especialistas da UFC, dando um apoio e instrução diversificada, visando contribuir para o mesmo objetivo.

Apesar dos Direitos Humanos serem pauta em discussão na conjuntura nacional, percebemos por meio dos relatos que suas ações de enfrentamento as violações dos Direitos Humanos estão longe de serem liquidadas por diversos fatores. Um deles diz respeito a falta de conhecimento e ao contexto econômico e político que enfrentamos na atualidade que aumenta a desigualdade em todos os seguimentos: econômicos, políticos e sociais. Nesta conjuntura também podemos destacar que as políticas públicas são insuficientes para atender a uma população que carece de atenção aos seus direitos básicos que são constantemente violados, por isso justifica-se a necessidade de projetos de extensão que visem a suprir parte dessa demanda. Vale ressaltar que o processo de construção da cidadania requer formação de cidadãos conscientes, e essa formação se dá pelas parcerias firmadas em prol de um único objetivo: amenizar os problemas da maioria vulnerável na tentativa de fazer valer seus direitos. 


\section{REFERÊNCIAS}

BRASIL. Diretrizes Nacionais para Educação em Direitos Humanos: Resolução $n^{\circ} 1$, de 30 de maio de 2012.

CRUZ NETO, Otávio, O trabalho de campo como descoberta e criação. In: DESLANDES, S. F.: CRUZ NETO, O.: GOMES, R.:MINAYO, M. C. de S (Orgs.). Pesquisa Social: teoria, método e criatividade. 21. Ed. Petrópolis, RJ: Vozes, p. 51 -66 2002.

DESLANDES, S. F.: GOMES, R.: MINAYO, M. C. de S (Org.). Pesquisa Social: teoria, método e criatividade. 28. ed. Petrópolis, RJ: Vozes, 2009.

GERHARDT, T. E.: SILVEIRA, D. T (Orgs). Métodos de pesquisa. Coordenado pela Universidade Aberta do Brasil - UAB/UFRGS e pelo Curso de Graduação Tecnológica Planejamento e Gestão para o Desenvolvimento Rural da SEAD/UFRGS. (Série Educação a Distância). - Porto Alegre: Editora da UFRGS, 2009. 120 p.

PORTAL G1, Universidade Federal do Ceará está entre as 15 melhores do Brasil. Disponível em: <http://g1.globo.com/ceara/noticia/2013/05/universidade-federal-do-cearaesta-entre-15-melhores-do-brasil.html> Acesso em 29 de ago de 2017. 